of the original protoplasmic verbal-nominal-interjectional form (as it seems to me), until words assume their present rigidity.

2. No one can examine the statistics given without being struck by the great differences in different children. $F$, in Mr. Tracy's tables, has 15 per cent interjections; while $K$, with a vocabulary of 250 words, has none at all. $F$ has II per cent adverbs; while $\mathrm{K}$ has but 2 per cent; in my own table, A has 4, while B has 9 per cent. So in my two, A has I I per cent adjectives; $B$, I per cent; while Mr. Tracy's vary from a maximum of 13 to a minimum of 3 per cent. I believe the tendency in all psychological investigation, at present, is to attempt to get a uniform mathematical statement, eliminating individual differences; for pedagogical and ethical purposes, at least, it is these differences which are, finally, most important. And on strictly psychological grounds the varying ratio of adverbs and pronouns on one side and nouns and adjectives on the other must denote a very different psychological attitude-different methods of attaching interest and distributing attention. Observation of different mental traits as connected with these linguistic differences would not only add to the terra incognita, individual psychology (and it would seem that all psychology must be finally individual), but throw great light upon the psychology of language. How vague and formal at present our answers, for example, when we are asked to what psychological state and need an adverb corresponds!

\title{
WORK AT THE YALE LABORATORY.
}

\section{BY E. W. SCRIPTURE.}

The first year in the life of a laboratory is one of incredible difficulties and incessant labor in getting matters arranged. Nevertheless, we have been able to carry on several investigations and bring them to succe'ssful conclusion and publication.*

The most extensive investigation was that by C. B. Bliss on reaction-time and attention. The graphic method was developed so that records absolutely accurate to thousandths of

* Studies from the Yale Psychological Laboratory, 1892-1893, edited by E. W. Scripture, New Haven, 1893. 
a second can be made and counted with less trouble than chronoscope records. The vibrating line receives a sparkrecord at the instant of the stimulus and another at the instant of reaction. The single waves, or sec., are counted and the odd tenths obtained by the eye. The necessary arrangement of the currents led to the invention of a multiple key. The reaction-time to sound was measured with and without disturbances of attention. When the attention was distracted by a steady light the disturbance of the reaction-time to sound was very small; with an unsteady, moving light it was very great. When the attention was disturbed by a steady sound, e.g., a tone, no disturbance resulted in the reaction to sound; with an intermittent sound, e.g., a metronome, it was very marked. In making these experiments some unexpected results were obtained, showing that the reaction-time to a sound heard in both ears is shorter than when the sound is heard only in one ear, even after making allowance for the difference in intensity.

Dr. Bliss made the attempt to determine the relation of changes in reaction-time to various other mental disturbances. After each set of experiments records were made of anything worth noting that had passed in the mind. The conclusions from these introspective observations are:

I. Reaction-time is constantly affected by irregular disturbances a large part of which may be detected by introspection.

2. Introspection is not to be trusted in estimating results.

3. Reactions to the wrong signal, reactions before the signal is heard, and the reflex nature of reactions are not sufficient criteria to distinguish muscular from sensorial reactions.

4. There are at least six distinct kinds of voluntary attention: ideational attention, neural attention, feeling attention, muscular attention, preparatory attention, and inattention.

5. The involuntary attention is constantly changing.

Experiments were made showing the influence of various distractions and mental operations on the rate of voluntary tapping and on the steadiness with which a lever could be kept at a given place. 
C. E. Seashore succeeded in making the first trustworthy measurements on the time required for altering the accommodation of the eye. $\mathrm{He}$ has established three important principles:

I. Within certain limits the accommodation-time varies with the distance between the points for which the eye is to be accommodated.

2. It takes longer to change the accommodation from near to far than from far to near, and this difference in time varies directly with the length of the accommodation-time.

3. For equal distances in the same range the accommodation-time is greatest for points near the eye and decreases with the distance of the points from the eye.

The investigations on reaction-time in relation to intensity and pitch, made by Dr. M. D. Slattery, lead to these conclusions:

I. The law that the reaction-time decreases with increasing intensity of stimulus does not hold good for the sense of hearing, i.e., the reaction-time to tones is nearly the same for all moderate intensities.

2. The longer time registered for very weak tones or noises by some observers is probably not due to any conscious change, but is caused by hesitation as to the actual hearing of the stimulus.

3. The reaction-time to tones decreases as the pitch rises.

4. The view held by Exner, von Kries, and Auerbach and rejected by Martius-namely, that about ten vibrations are necessary to the perception of a tone, no matter what its pitch -is sufficient to explain the differences in the reaction-times for different tones.

5. In the domain of tactile stimulation by electricity the reaction-time decreases with the increase in the intensity of the stimulus.

The experiments of J. A. Gilbert on the musical sensitiveness of school-children involved in the first place the invention of a new piece of apparatus, the tone-tester, which has proved an exceedingly convenient instrument for much demonstrational work on the psychological methods. The sensitiveness to differences in pitch increases with age; at first rapidly, then 
very slowly. The least perceptible difference at 6 years is $\frac{12}{32}$ of a tone, at 19 years it is $\frac{2}{32}$. At 10 years and at 15 years the sensitiveness suddenly falls off.

A new reaction-key, designed to avoid the objections to the usual telegraph-key, is described in an article on the time of voluntary movement. Being a new instrument it opened up new methods of solution; one of these was the measurement of the time of voluntary movement. The time of flexion of the finger was found to decrease as the distance of movement increased from $5 \mathrm{~mm}$ to $20 \mathrm{~mm}$; the time of extension, however, increased. This is explained by J. M. Moore as the result of the favorable leverage for the flexor muscles at the smaller distances.

An article on drawing a straight line makes the attempt to apply experimental methods to pedagogical problems. The average errors for various positions, inclinations, grasps of the pencil, etc., were determined.

The equipment of the workshop in the laboratory has proved an excellent investment. The room is the one most used in the building and is often quite overcrowded. To have accomplished without a workshop the amount of work actually done in the laboratory would have cost more than the two hundred dollars spent in its equipment; thus at the beginning of the second year we are in possession of a well-equipped workshop which has already paid for itself. The employment of a mechanic has furnished the opportunity for the invention of several pieces of apparatus. The multiple key has been much improved in a later model. A novel clock contact makes platinum contact in the middle of the arc of swing. A new drum built with the durability of a piece of machinery is run either by hand or by motor. 